\title{
Anosmia, CTCAE
}

National Cancer Institute

\section{Source}

National Cancer Institute. Anosmia, CT CAE. NCI Thesaurus. Code C143230.

A disorder characterized by a change in the sense of smell. 